\title{
AERO-THERMAL UPGRADE OF TURBINE SECTION IN MAPNA HEAVY-DUTY GAS TURBINE MGT-70(3)
}

\author{
Amir Poursamad*, Hamid Motamedi Zo
Arash Bahramitalab*, Shahriar Abedin
* MAPNA Turbine Engineering \&
Manufacturing Co. (TUGA) \\ Fardis Road, Karaj, Iran
}

Email: Poursamad.Amir@mapnaturbine.com

\begin{abstract}
In this paper, the process and results of aero-thermal upgrade of turbine section in MAPNA heavy-duty gas turbine MGT-70 is presented. The upgrade has been aimed at improving turbine efficiency and power output, while maintaining or increasing parts life. Aerodynamic optimization of vanes and blades airfoils is performed using a full 3D aerodynamic optimization approach to maximize aerodynamic efficiency of the gas path. The internal cooling system of vanes and blades are then redesigned for optimized airfoils and new thermal conditions. In the upgraded thermodynamic cycle of the gas turbine, turbine inlet temperature (TIT) is increased by $30{ }^{\circ} \mathrm{C}$. The main target of cooling system redesign has been to maintain or improve vanes and blades life in the new hot gas conditions without increasing the total amount of coolant flows. Cooled rows are coated with thermal barrier coating (TBC) and all vanes and blades material is also enhanced. Some secondary air system (SAS) elements and seals are also modified to conform to new cooling and sealing requirements and to reduce the leakages. All modifications are performed considering retrofit concept as a constraint.

The redesigned vanes and blades are manufactured and installed during overhaul in one of MGT-70 units planned to be upgraded. Test results show that the upgrade has been successful and the power and efficiency have surpassed the target values. Beside standard performance test, extensive tests are also conducted in order to validate the redesign process and tools, and also monitor the turbine during operation. Detailed measurement of temperature, pressure, and flow are performed in various locations in flow path and secondary air system.
\end{abstract}

\section{INTRODUCTION}

MAPNA gas turbine MGT-70 is a $50-\mathrm{Hz}$ E-class heavyduty gas turbine which is utilized for power generation in simple and combined cycle. More than 170 units of different versions of this gas turbine are in commercial operation in Iran and neighboring countries. Owners are usually interested to improve the performance of their assets by increasing output, improving efficiency, enhancing reliability, extending components life, and reducing maintenance costs. It is always economically attractive to owners to achieve such improvements by upgrading their installed turbines.

For this reason, during the past years, various $R \& D$ projects have been launched in MAPNA Group in order to continually improve the performance, remove weak spots, and increase reliability and availability of MGT-70 gas turbine. Successful upgrade experiences of the turbine section in MGT-70(1) and MGT-70(2) versions are some examples of such ongoing improvements. The main focus of these two upgrades has been on improving materials and coatings with minor changes in components design. As a major step forward, a new turbine section upgrade is introduced in MGT-70(3) which can be combined together with the compressor upgrade package to form a new version of the machine.

Advances in design and modeling of aerodynamics, cooling and heat transfer, as well as sealing technologies, have paved the way for MAPNA Group towards an optimized, highly efficient gas path in MGT-70(3). Furthermore, using more advanced materials and coatings has also provided room to operate the hot gas path components for longer intervals in more severe conditions with higher temperature levels. 
The upgrade process in MGT-70(3) aimed to increase power and efficiency, while maintaining the targeted life of the components for better reliability and availability. The Eclass design concepts are maintained in order to stay within E-class production and maintenance costs, and to avoid imposing any further limits on fuels at the same time. Moreover, considering the numerous operating machines in this fleet, together with the fact that the turbine vanes and blades have to be replaced during standard major outages, the new upgraded turbine section is designed to be available as a retrofit.

All vanes and blades in the turbine section are redesigned to achieve a highly efficient gas path. This includes 3D optimized airfoils, redesigned cooling systems, and enhanced sealing elements for all vanes and blades. The redesign process is started with aerodynamic optimization of vanes and blades outer profiles. Then, the cooling system of vanes and blades are adapted and redesigned to match the new profiles and to improve the cooling performance. The new vanes and blades material are changed to an improved Ni-base material, coated with enhanced bond coat, enhanced TBC, and internal aluminide coating. Finally, some SAS components are changed to match the new cooling system, and also, some seals are replaced with new enhanced seals to minimize leakages.

This paper describes the aero-thermal design process and results in MGT-70(3) turbine section upgrade. First, a brief description of the gas turbine configuration and main characteristics is presented. Then, the redesign activities and results in thermodynamic cycle, aerodynamic, cooling, and SAS are discussed. Finally, performance test results and the measurements performed in prototype testing are explained.

It should be mentioned that due to paper length limit, only a general overview of the above mentioned steps and overall results are presented in this paper. In fact, the big picture of the upgrade process is provided in this paper and more technical details and results will be presented and discussed in other publications.

\section{MGT-70 GAS TURBINE}

Figure 1 illustrates the general configuration of MGT-70 gas turbine. It has a 16-stage axial flow compressor, with a row of variable Inlet Guide Vane (IGV) featuring a fast acting option for grid frequency control. The combustion system consists of two external silo-type combustors, each of which having 8 hybrid burners suitable for operation with gaseous or liquid fuels. The turbine section includes 4 stages ( 8 rows) of conventionally cast vanes and blades. The first 5 rows, i.e. vanes and blades of the first and the second stages and vane of the third stage, are convectively cooled. The turbine is followed by an axial exhaust diffuser which directs the exhaust flow axially toward the stack in simple cycle or heat recovery steam generator (HRSG) in combined cycle. The casings are horizontally split including outer casing and separate vane carriers to accommodate thermal expansion. The rotor is of single shaft disc-type construction with radial Hirth-serrations and one central tie rod. It is supported by a combined thrust and journal bearing at compressor end and a journal bearing at turbine end. The output flange is on the compressor end. This gas turbine is combined in a $2 \times 1$ configuration with MAPNA steam turbines MST-50C or MST-55C in combined cycle power plants (CCPP).

MGT-70(3) is the latest upgrade of this machine in which extensive modifications are applied to compressor and turbine sections compared to the baseline MGT-70. As mentioned earlier, all vanes and blades in the turbine section are $3 \mathrm{D}$ redesigned and some seal elements are improved. The compressor section upgrade involves $3 \mathrm{D}$ redesign of the first 4 stages. Hot gas casing is also coated with TBC to withstand higher temperatures. Furthermore, the thrust bearing is modified to be able to accommodate higher thrust forces exerted on the rotor.

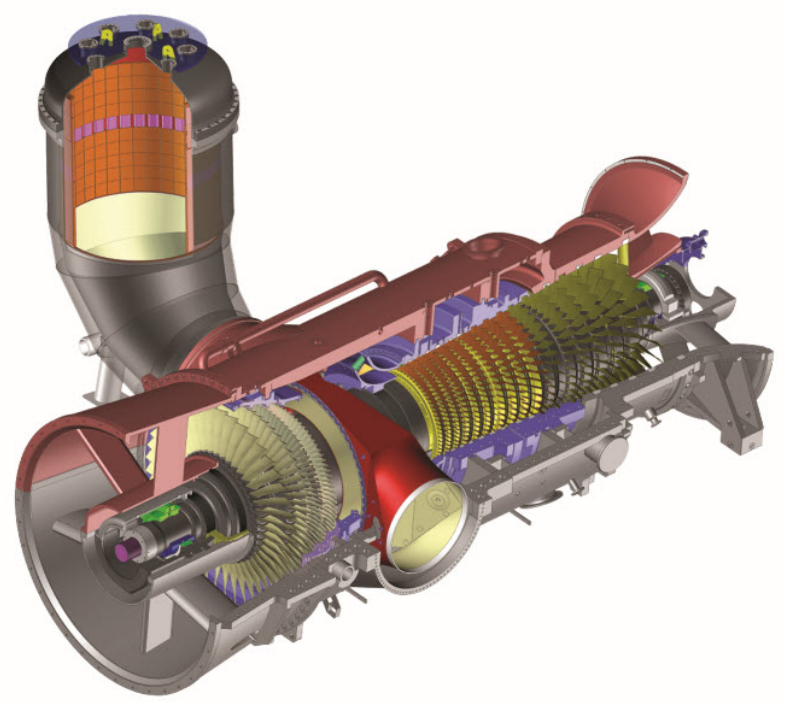

Figure 1. MAPNA heavy-duty gas turbine MGT-70

\section{THERMODYNAMIC CYCLE REDESIGN}

Parametric study on thermodynamic cycle of the gas turbine is performed to select the optimal cycle parameters. The thermodynamic cycle is redesigned to maximize CCPP efficiency considering retrofitability and E-class technological constraints. As a result, in the upgraded turbine, TIT is increased by $30^{\circ} \mathrm{C}$. With an increased target inlet mass flow of $544 \mathrm{~kg} / \mathrm{s}$ and pressure ratio of 12, together with target improvements in components efficiencies, the output power and efficiency of the new machine are targeted to reach $183 \mathrm{MW}$ and $36 \%$ respectively, compared to 157 MW and $34.4 \%$ of the baseline machine in ISO reference conditions.

\section{TURBINE VANES AND BLADES AERODYNAMIC OPTIMIZATION}

The aerodynamic optimization of the turbine flow path, including all vanes and blades airfoil profiles, is accomplished utilizing latest 3D aerodynamic design and optimization approaches coupled with computational fluid dynamics (CFD). 
First, a high-fidelity multi-stage CFD model of the turbine flow path is set up (Fig. 2). A lot of details are considered in the model, including inlet and exhaust effects, cooling, sealing, and leakage flows, end-wall cavities, TBC layer effect, end-wall fillets of all vanes and blades, and so forth. This high-fidelity multi-stage CFD model is validated and improved using extensive performance test results performed on MGT-70 fleet. This model is utilized, on a comparative basis, for evaluation of modifications made through the upgrade process.

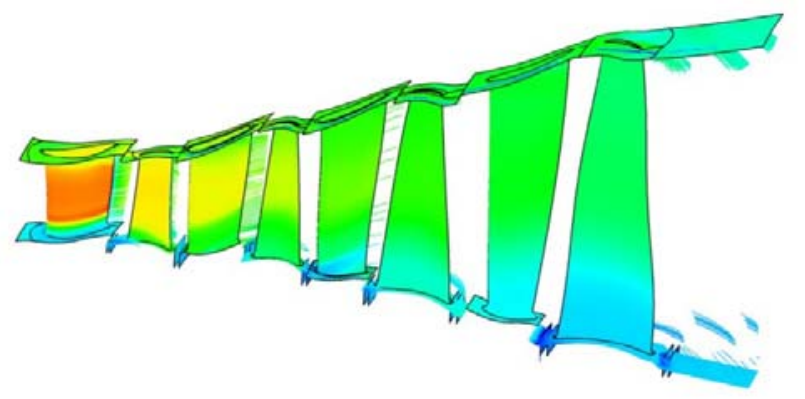

Figure 2. Turbine high-fidelity multi-stage CFD model

Structured multi-block meshes are implemented with pre-defined topologies for each row to make the comparison of the baseline and redesigned vanes and blades more accurate by excluding numerical differences caused by the grids. Sensitivity analyses are performed to find the most important mesh parameters and also to insure grid independency. The final computational domain consists of about 9 million meshes for flow path and 1 million grids for cavities. End-wall cavities are meshed separately and mated with the main flow path using non-matching boundary condition setup.

A real-gas model is used in CFD calculations in order to consider combined effect of variation of temperature and gas composition along the gas turbine flow path. In this thermodynamic model, flue gas mixture is considered thermally perfect and heat capacity varies as a function of temperature and fuel air ratio. One-equation SpalartAllmaras turbulence model (Spalart and Allmaras, 1992) for turbulence closure is used with standard wall function for near wall treatment. All simulations are performed as steadystate Reynolds-Averaged Navier-Stokes (RANS) and mixing plane approach is used for rotor-stator interface modeling.

Inlet boundary conditions for this model are extracted from a complete 3D CFD model of the combustor. This model consists of both combustion chambers and first turbine vane row. Similarly, outlet boundary condition is obtained from a 3D CFD simulation of diffuser and exhaust system in interaction with the turbine model. Cooling, sealing, and leakage flows are prescribed as injections. Coolant flows are resulted from conjugate heat transfer (CHT) analyses of each cooled row and sealing and leakage flows are obtained from a 1D flow network model of the whole SAS. Both CHT and 1D flow network models exchange boundary conditions with the multistage CFD model.
Aerodynamic redesign and optimization of the turbine vanes and blades is performed using a combination of CFDbased and surrogate-based optimization approaches. Neural networks are employed as surrogate model and genetic algorithms are utilized as optimization tools.

Parameterized 3D model of each vane and blade is constructed and design variables, including airfoil construction curves and 3D stacking parameters, are selected based on numerous design of experiments (DoE) and sensitivity analyses. Since the number of underlying design parameters for the whole turbine vanes and blades airfoils are too huge to be dealt with in a single optimization, the aerodynamic optimization process is decomposed into three steps, each of which involving a set of design variables targeting certain aerodynamic characteristics of the flow.

At the first step, the expansion line of the turbine is aimed to be optimized, to get a more uniformly distributed stage drops between all stages. Stagger angle at two airfoil sections of stator and rotor blades, namely hub and shroud, are considered as design parameters in this step, while the other geometric parameters of turbine blade and flow path remain unchanged. It should be noted that in this step of optimization, stagger angles of all vanes and blades are modified simultaneously in order to ensure the best matching between successive rows. Stage pressure ratios of the baseline and upgraded turbines are compared in Fig. 3. As can be observed, the stage loading distribution is modified in such a way that the first stage is de-loaded and a continuous increase in pressure ratio is resulted from the first to the last stage.

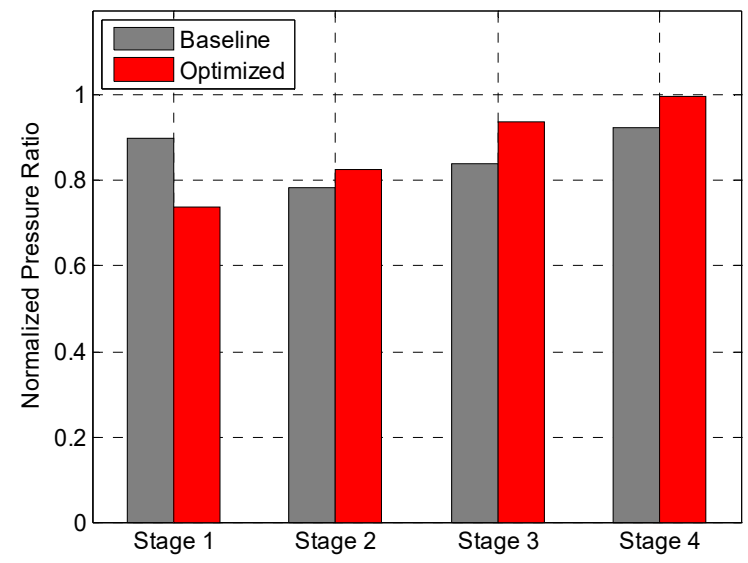

\section{Figure 3. Pressure drop distribution in turbine stages}

The focus of the second step is mainly on optimizing the radial distribution of flow parameters in each stage. In fact, the vortex design is further optimized in this step and inappropriate incidence angles are also corrected. In this step, optimization is performed for each stage separately in the multistage framework. It means that the design parameters for the vane and blade of the target stage are changed while all other vanes and blades geometries are fixed from the previous step. Each blade or vane is defined by three or five 
sections at different span-wise locations. Camber line at each section is modified through this step of optimization, while blade thickness distribution is still unchanged. A 3-parameter Bezier cure is used to define chamber line, the design variables of which includes inlet and outlet metal angles, as well as airfoil stagger angle. This leads to a total number of 9 or 15 parameters per blade row. Even though stagger angles of each vane and blade are specified in the previous design step, its radial distribution can be modified in this step in such a way that the total stages drops remain constant. Figure 4 shows how radial distribution of reaction degree for instance is modified in a typical stage as a result of the second step of optimization.

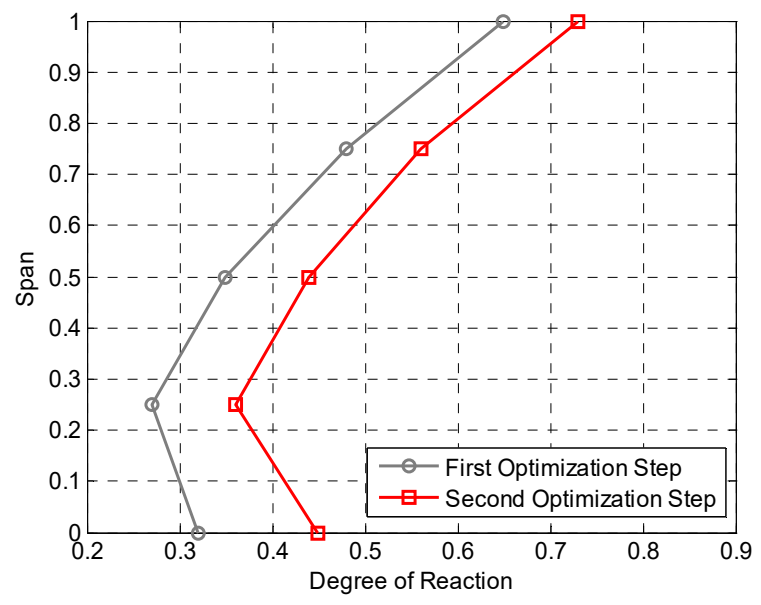

Figure 4. Radial distribution of degree of reaction in a typical stage

Finally, at the third step, airfoil profiles are optimized for each individual row. The target of this re-profiling is to obtain a velocity distribution along blade suction and pressure surfaces which minimizes the aerodynamic losses. In this step, the camber line and suction and pressure side curves defining the airfoil, as well as stacking lines of vanes, are subject to optimization process. Bezier curves are used to define airfoil camber, side curves and stacking lines. Suction and pressure surfaces are parameterized using 5 or 6 control points. Camber curve is modeled with 4 control points to increase the possibility of finding optimum geometry. Radial stacking lines of vanes are also parameterized with 3 control points to introduce lean to $3 \mathrm{D}$ geometries. This step of optimization is conducted separately for each row in the multistage model. Loss minimization is achieved in this step by such improvements as eliminating shocks, reducing flow separations, and so forth, as can be seen, as an example, in Fig. 5 and Fig. 6.

It should be noted that in the new design, not only 2D profile loss of blades and vanes is reduced, but also a considerable amount of effort has been made to reduce 3D losses, including tip leakage loss and secondary loss associated with the turning of the boundary layer near the end-wall regions. The effectiveness of this full 3D design and optimization technology is more pronounced by comparing losses caused by 3D flow structures as observed for a typical row in Fig. 7.
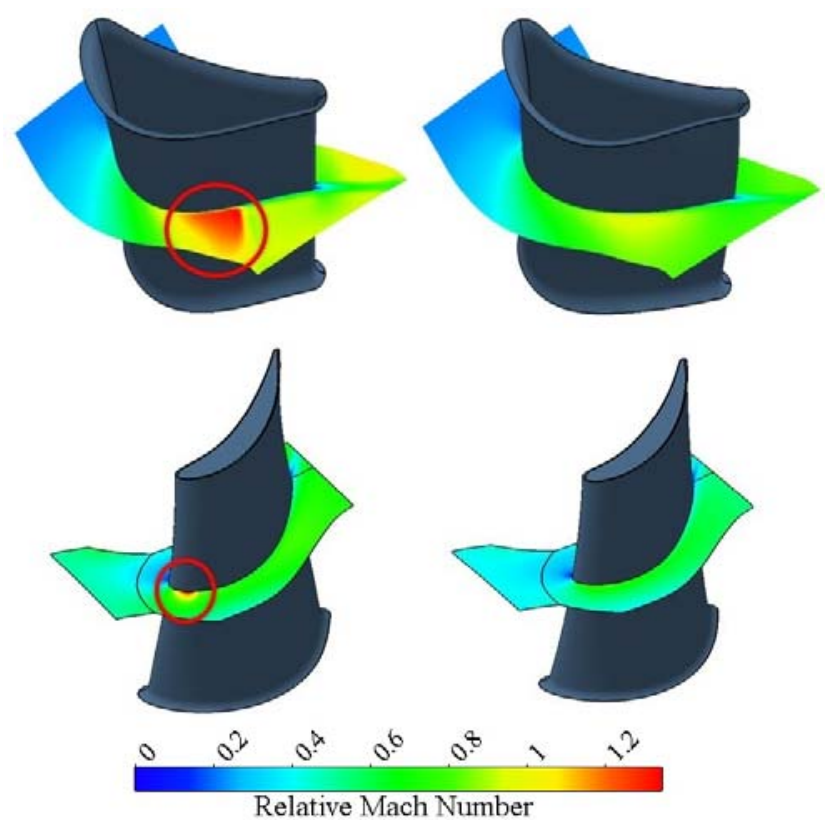

Relative Mach Number

Figure 5. Blade-to-blade contour of Mach number at mid-section in a stage of baseline (left) and upgraded (right) turbine
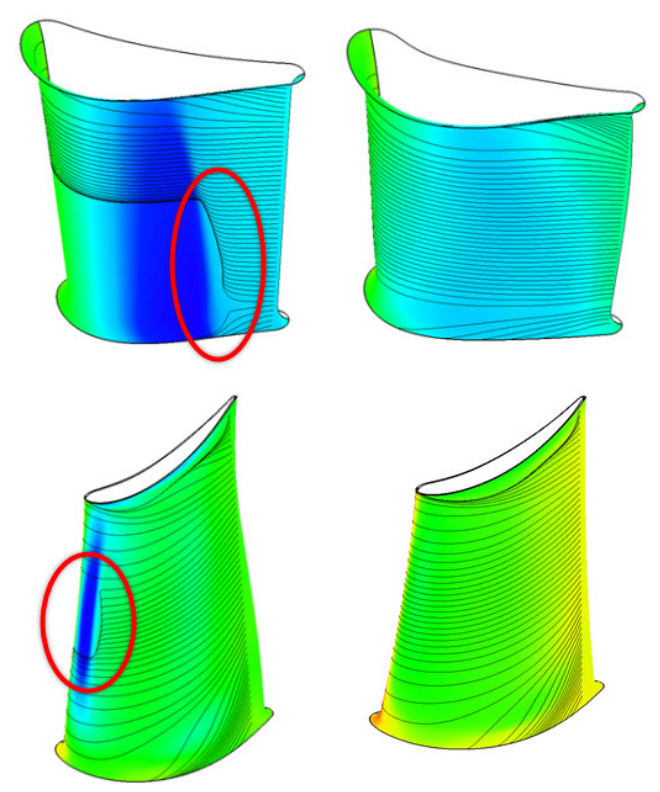

Figure 6. Static pressure contour and separation line for a vane and blade of baseline (left) and upgraded (right) turbine

Normalized turbine blading efficiency for each stage, before and after the above mentioned aerodynamic optimization approach, is compared in Fig. 8. The efficiency of cooled stages is calculated based on the approach proposed by (Young and Horlock, 2006). 


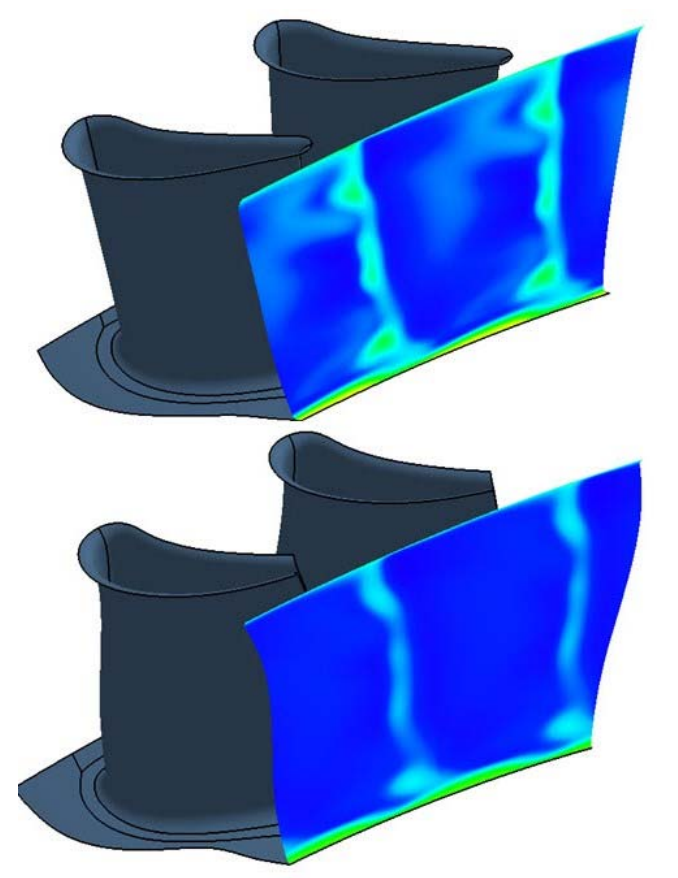

Figure 7. Pressure loss coefficient contour at a row outlet of baseline (top) and upgraded (down) turbine

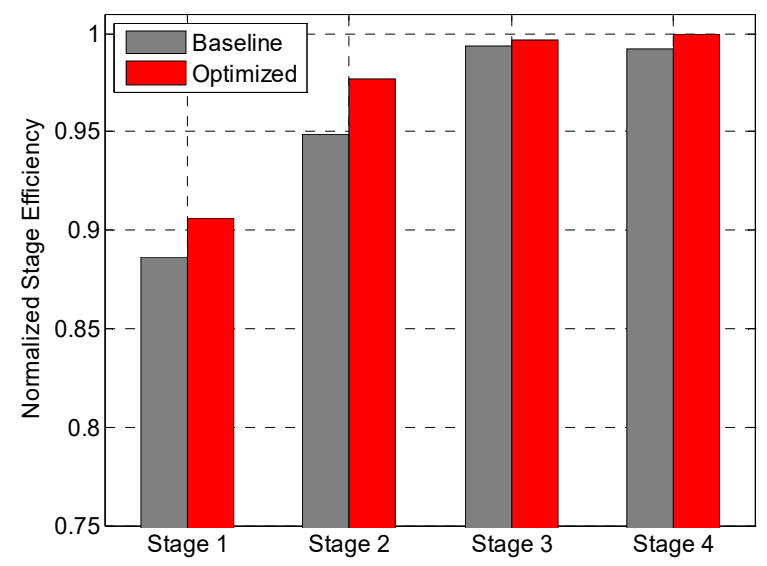

Figure 8. Normalized stage efficiency

\section{TURBINE VANES AND BLADES COOLING SYSTEM REDESIGN}

As a result of aerodynamic optimization, the outer profiles of vanes and blades airfoils and the hot gas conditions at the inlet of each row is changed. As mentioned earlier, in MGT-70(3), TIT is also increased by $30^{\circ} \mathrm{C}$. These new conditions required new cooling system for cooled vanes and blades.

The turbine cooling system must be designed to ensure that the maximum blade surface temperatures and temperature gradients during operation are compatible with the maximum blade thermal stress for the life of the design (Han, et al., 2013). The main target of cooling system redesign is to maintain or improve components life in the new, more severe, hot gas conditions without increasing the total amount of coolant flows or even decreasing it.

Utilizing cooling design and heat transfer modeling techniques, reduced-order models and high-fidelity CHT simulations are established to predict heat transfer, temperature distribution, and peak metal temperature in turbine vanes and blades, as well as coolant flow velocity and pressure drop. These models are used to evaluate the performance of cooling system during design iterations.

Reduced-order models based on simple conduction models for vanes and blades metal and 1D flow network models for internal cooling system are utilized in preliminary stages of cooling design. These 1D models specify coolant flow pressure drop and also provide thermal boundary conditions of blades internal surfaces for conduction modeling. External boundary conditions are extracted from multistage CFD simulation.

For detailed design, to obtain metal temperature distribution, high-fidelity CHT simulations are conducted where one solid and two fluid domains are considered and connected via interfaces for each cooled row. All CHT calculations follow predefined calculation procedure and physical settings to make comparison of redesigned and baseline metal temperatures viable. The fluid domain considers a two gas component model, which handles the hot combustion gas and pure cooling air fluid properties separately. The dynamic viscosity and thermal conductivity of the hot gas and coolant flow, as well as metal thermal conductivity, are considered defined to be dependent on temperature.

The mesh of the computational domain consists of 15 to 20 million unstructured cells, depending on the complexity of cooling system. On the interfaces, prism layers are applied on fluid side, to keep the wall $y^{+}$values around 1 and a grid expansion ratio of 1.2, to allow accurate resolution of flow field features and temperature gradients within the metal.

Total pressure and temperature and flow direction are prescribed at hot gas inlet boundary conditions and static pressure at outlet. These boundary conditions are extracted from multistage CFD simulation. Coolant total pressure and temperature derived from 1D model the whole engine are set as coolant side boundary conditions. All CHT simulations are performed as steady state 3D RANS, and k- $\omega$ shear stress transport (SST) turbulence model (Menter, 1994) is used for turbulence closure.

The cooling systems of vanes and blades in the baseline MGT-70 are confined to internal cooling. In the new design, this concept is still in place, i.e. no film cooling is added, in order to maintain the production costs within E-class machines, and also, to maintain fuel flexibility of the gas turbine.

In vane 1 , impingement cooling is the major cooling method together with nubs in the mid-chord region and pinfins near the trailing edge. The impingement holes and nubs size and distribution are modified. The pin-fin arrangement is also optimized in terms of number, diameter and distribution. Another improvement in the cooling system design in MGT- 
70(3) is pressure side cooling air ejection instead of previously used trailing edge ejection wherever applicable. This provides the possibility of reducing the trailing edge thickness and decreases the aerodynamic losses. Figure 9 shows how the trailing edge cut-back is replaced with a new pressure side cut-back in vane 1 .
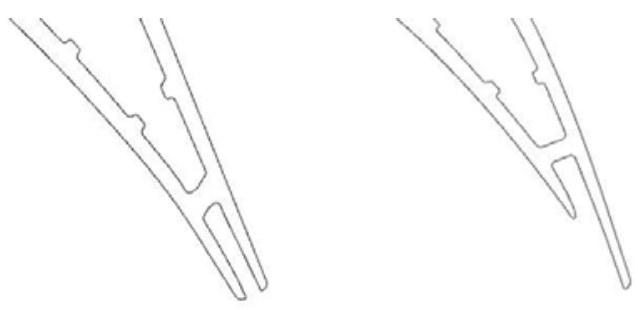

Figure 9. Coolant ejection from trailing edge cutback in baseline (left) and pressure side cut-back in upgraded (right) turbine

The cooling scheme of blade 1, together with CHT simulation results performed in the final detailed design of cooling system, are presented in Fig. 10. This blade uses serpentine cooling passages with rib-turbulators along the path and pin-fins near the trailing edge. The shape, size and arrangement of ribs and pin-fins are modified and pressure side cut-back is implemented here.
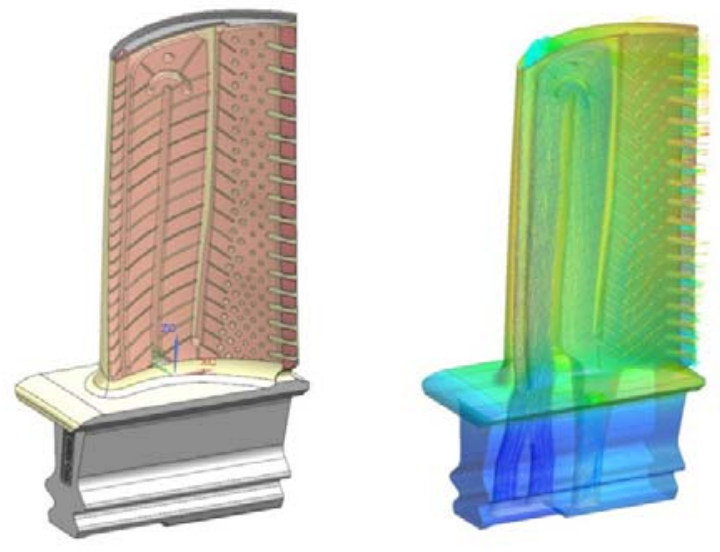

Figure 10. Blade 1 cooling system configuration and $\mathrm{CHT}$ simulation results

For vane 2, impingement cooling is maintained, with modified impingement holes. Pin-fins are also added near the trailing edge, and the trailing edge ejection holes are modified. Radial cooling bores are kept in blade 2, but the number, size and diameter of the bores are changed. For vane 3 , the simple cavity is redesigned with some ribs and fins added to the cooling system. Some trailing edge ejection holes are also added to cool the trailing edge.

It should be mentioned that for all vanes and blades, comprehensive mechanical analyses are also performed which are not discussed in this paper. These analyses include vibration analyses, mechanical integrity investigations, aerothermo-mechanical stress calculations, fatigue and creep analyses.
All vanes and blades material is modified to an improved superalloy with superior strength, particularly from creep life point of view. Moreover, cooled vanes and blades are coated with enhanced TBC. To provide protection from corrosion and oxidation, improved bond coat and internal aluminizing are also applied.

Metal temperature distribution at mid-span on the outer surface is compared for a typical row of the baseline and upgraded turbine in Fig. 11. It can be observed that temperature gradients, average temperature level and maximum temperature are reduced by the upgraded cooling system.

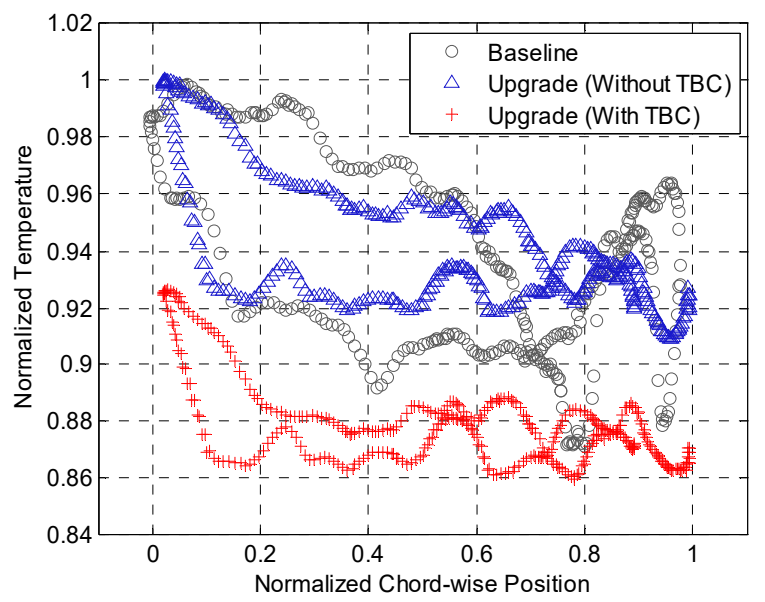

Figure 11. Metal temperature distribution at midspan on the outer surface

Considering the fact that TIT is increased in MGT-70(3), together with the effect of redistribution of stage loadings, vanes and blades are exposed to more rigorous hot gas path conditions in the upgraded turbine. However, better cooling design with improved cooling efficiencies, advanced superalloys with higher thermo-mechanical resistance, and enhanced coatings has improved vanes and blades life.

\section{SECONDARY AIR SYSTEM COMPONENTS AND SEALS MODIFICATIONS}

Secondary air system plays a vital role in modern gas turbines, serving to dissipate windage and heat conducted to the discs, deliver air for turbine blade cooling, maintain the required axial pressure loading on the bearings, prevent hot gas ingestion from the main annulus to disc spaces, and to isolate the oil system (Chew and Hills, 2007). All these functions are monitored through the upgrade of turbine and compressor vanes and blades in MGT-70(3).

An extensive 1D flow network model of the whole SAS from compressor extraction points up to turbine injection points is set up. A section of this model is demonstrated in Fig. 12. This reduced-order model comprises a network of interconnected lumped models of SAS elements. Correlations are used in each lumped element to model flow and heat transfer in that specific element. These correlations are tuned based on numerous CFD simulations and also some test results to achieve a reliable 1D network model capable of 
predicting pressure losses and temperature rises due to windage and wall temperatures.

This 1D model is used for simulating the overall flow behavior and distribution. This model is iteratively used during aerodynamic optimization and cooling system redesign of turbine vanes and blades to insure the efficient delivery of enough cooling and sealing flows. Throughout aerodynamic optimization, the amount of rim cavity sealing flows are determined by this model and compared to minimum sealing flow required to prevent hot gas ingestion into disk spaces. Boundary conditions are iteratively exchanged between this model and vanes and blades cooling system to assure that coolant mass flow and pressure are matched with SAS. Furthermore, this model is also used to calculate and update the leakage flows.

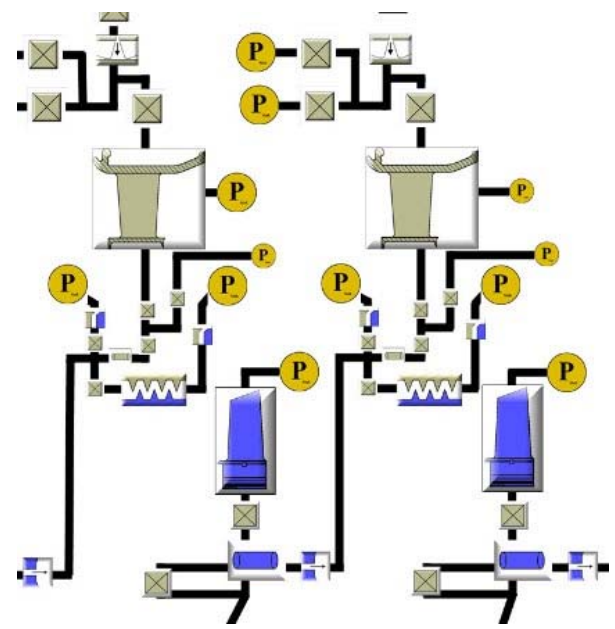

Figure 12. A section of whole SAS 1D model

The 1D flow network is coupled with a thermal model of the whole engine. This thermal model calculates the heat transfer and wall temperature distribution in rotor parts and casings, in different design and off-design points. Wall temperature distributions are used in a finite element model of the whole engine to calculate axial and radial clearances in steady-state and transient operating modes. Furthermore, the 1D model is linked to a thrust calculation model which is used to assess the rotor thrust changes resulted from upgraded turbine and compressor vanes and blades.

In addition to $1 \mathrm{D}$ simulations, high-fidelity $3 \mathrm{D}$ CFD simulations are performed for rim cavity sealing assessment in all turbine rows. Stator-rotor cavities sealing path, together with mainstream flow, including upstream and downstream vanes/blades, are modeled considering all geometrical details. Rim cavity sealing performance is investigated considering the interaction of main and secondary flows in rim area. These CFD simulations are performed as steady state 3D RANS, using k- $\omega$ SST (Menter, 1994) for turbulence model. In order to be able to track sealing air/hot gas interactions, a multi-component approach is implemented where two gasses with different chemical compositions are assigned to sealing flow and to main flow. A typical example of such analyses is depicted in Fig. 13 (Banihabib and Poursamad, 2019). Due to enormous computational cost of such simulations, these simulations are not performed during optimization iterations and are only conducted for the optimized vanes and blades and are compared to the baseline machine.

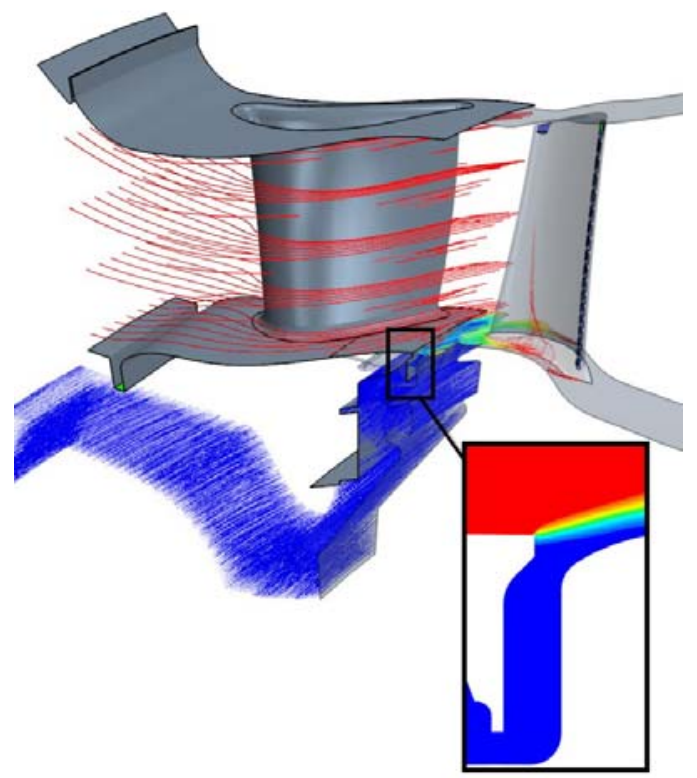

Figure 13. Rim cavity sealing performance assessment in the upgraded turbine

As a result of these investigations, a few components of the SAS have had to be modified due to changes applied in the flow path and vanes and blades cooling systems. In order to conform to retrofitability concept, only those SAS components that could be replaced or modified during standard major outages are made subject to change. The baffle plates in the third cavity of vane carrier are modified to better guide the cooling air to the new vane 3 and improve its cooling. The seal ring of the third vane is also modified to regulate the sealing air flow in the rim cavity and to adapt to new thermal conditions of the third vane.

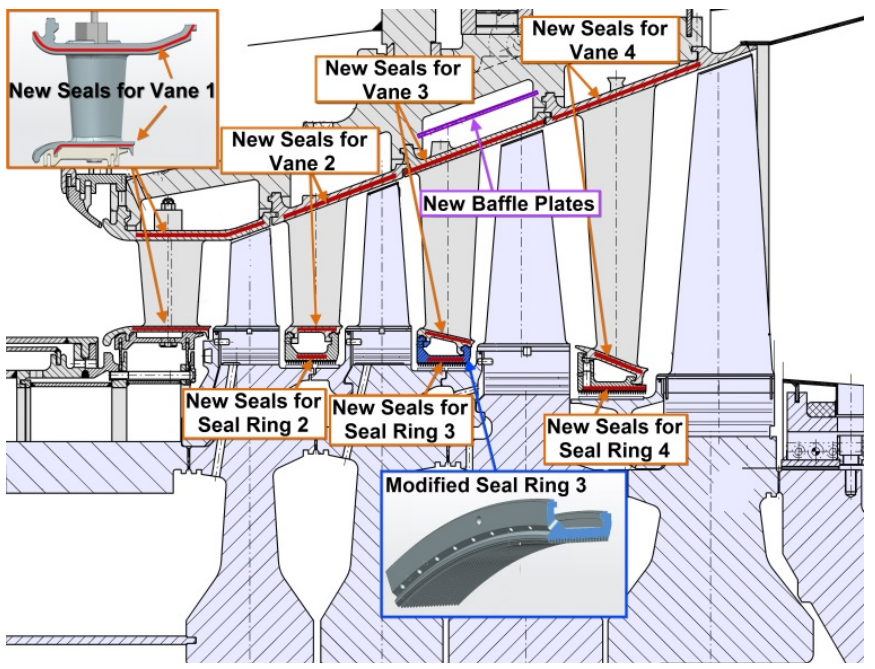

Figure 14. SAS and seals modifications in the upgraded turbine 
Another improvement that is carried out in MGT-70(3) is the reduction of leakage flows. All seal strips between vane segments and between seal ring segments are replaced with new enhanced seals in order to reduce the leakage flows. A schematic of turbine section, presenting modifications in SAS components and seal elements, is shown in Fig. 14.

\section{TURBINE TESTING AND VALIDATION}

The first set of upgraded vanes and blades, together with modified seals and SAS elements, were manufactured and installed in the spring of 2017 during overhaul of an MGT-70 unit planned to be upgraded in Parand power plant, southwest of Tehran (Fig. 15). The scope of upgrade for the turbine section included:

- New vanes and blades (with optimized aerodynamic and cooling), with new Ni-base material, enhanced bond coat, enhanced TBC, internal aluminide coating

- New baffle plate for vane 3

- New seal ring for vane 3

- New seal strips for all vane segments

- New seal strips for all seal ring segments

- Control system adjustments

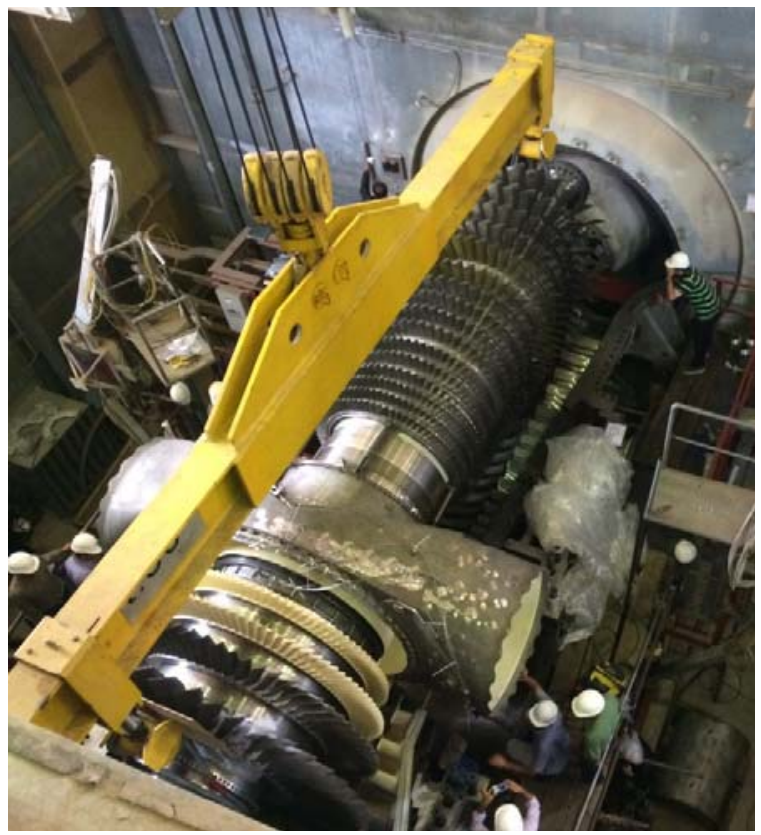

Figure 15. Installation of upgraded parts together with instruments in Parand powerplant

Two sets of tests, including performance guarantee test and design validation tests, are conducted on this machine. In addition to standard performance test, an extensive test program is carried out in order to validate the turbine design. The test program includes numerous pressure, temperature, and flow measurements in hot gas path and SAS and also hot gas parts metal temperature measurement. These measurements are intended to validate design and analysis tools for aerodynamics, cooling, and SAS. Sensors are installed in various circumferential and radial locations and all parameters are measured in steady-state and transient operating modes. Test results are acquired and analyzed for different operating conditions, including baseline and various off-design conditions. A schematic of the turbine illustrating the majority of measurements in turbine section is shown in Fig. 16. It should be noted that some other measurements, such as blade tip clearances, vibration, and vibratory stresses are also performed which are not presented in this paper. Numerous instruments are also installed on compressor section which are not discussed here but are used for validation of compressor and also SAS.

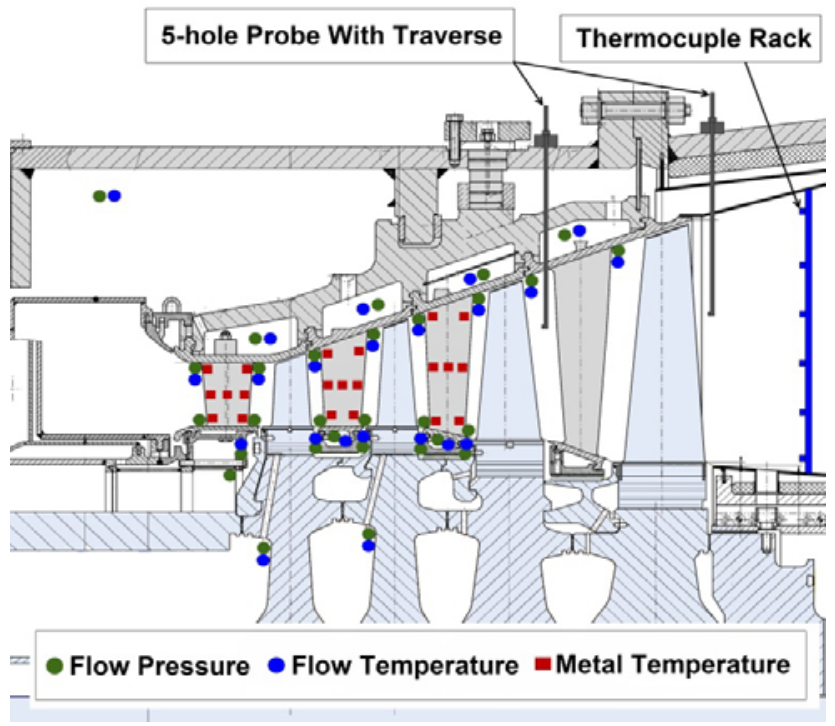

Figure 16. Schematic of measurement points

The main target of aerodynamic measurements is to validate that the intended turbine expansion line, stage matching and vortex design are met. Static pressure is measured throughout turbine flow path in different axial positions from turbine inlet to exit. Pressure taps are installed on vanes inner and outer platforms near leading edge and trailing edge axial position. In each stage of the turbine, three vanes in different circumferential positions are instrumented to insure enough redundancy and also capture pitch-wise asymmetries. Thermocouples are also installed in some locations on vanes outer platforms.

Five-hole probes with traverse system, as shown in Fig. 17, are utilized for measuring radial distribution of flow parameters downstream and upstream of stage four in two different circumferential positions. Total and static pressure, as well as total temperature are measured by the probes and flow direction and velocity components and Mach number are calculated. Fixed rack of thermocouples are also installed in turbine exit in the lower half, where traversing is not possible, to capture circumferential distribution of flow temperature.

For thermal design validation of turbine components, thermocouples are used for metal temperature measurement in vanes of the first, second, and third stages. In each row, vanes are instrumented in three different circumferential positions. Thermocouples are installed in the wall in several chord-wise and span-wise positions in different vanes. A 
typical example of thermocouple installation for the first vane is illustrated in Fig. 18. A full thermal design validation for all vanes and blades by thermal paint is also planned to be carried out in another unit of MGT-70(3).

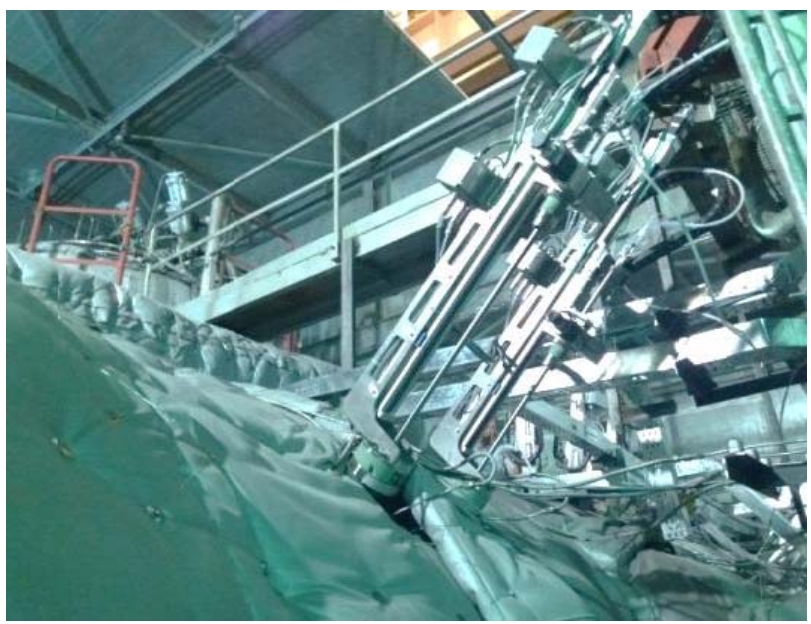

Figure 17. Five-hole probes with traverse system for gas path aerodynamic measurements

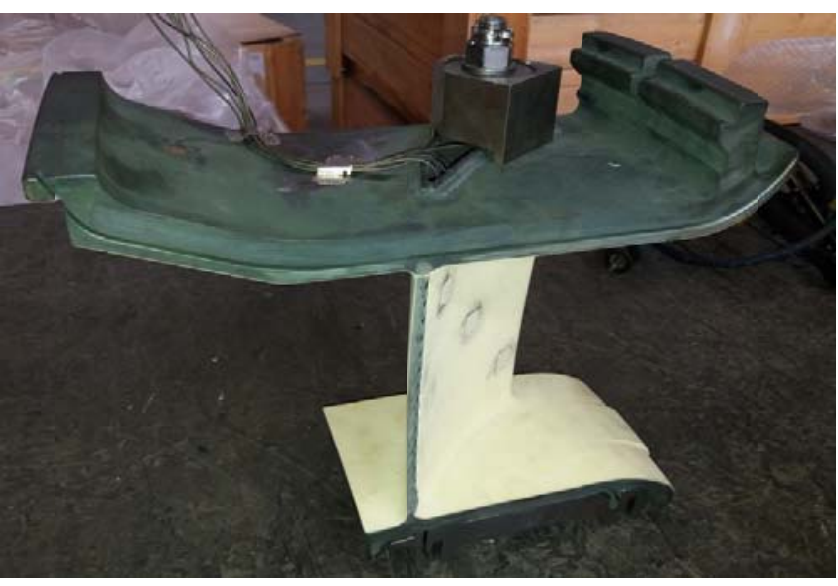

Figure 18. Vane metal temperature measurement using thermocouples

In addition to main flow path, several measurements are also performed in SAS in order to complete the design validation of cooling system in interaction with SAS and also to make sure that the upgraded hot gas path is properly sealed. Flow pressure and temperature are measured in different cooling and sealing air paths for stationary and rotary parts. Contact-free telemetry system is employed for data transfer from measurements in rotary parts (Fig. 19). Piezo-electric sensors are used for pressure measurement in rotary parts. Mass flow rate is measured in external cooling extraction pipes by annubar flowmeters. Thermocouples and pressure taps are installed in stator-rotor cavities to evaluate rim cavity sealing performance and insure prevention of hot gas ingestion into disk spaces (Fig. 20).

Throughout this test program, the unit is operated through a full range of steady-state and transient operating conditions. Measurement results are compared with simulation results and assessments shows that they are within expectations. Design and analysis tools are being improved by processing of these measurement results. Detailed comparison of simulations and tests results is beyond the limits of this paper and will be presented in other publications.

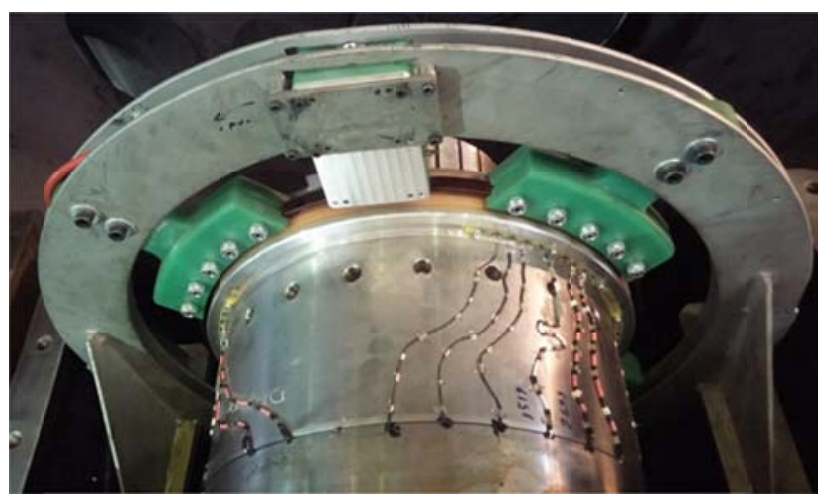

Figure 19. Telemetry system for data transfer from measurements in rotary parts

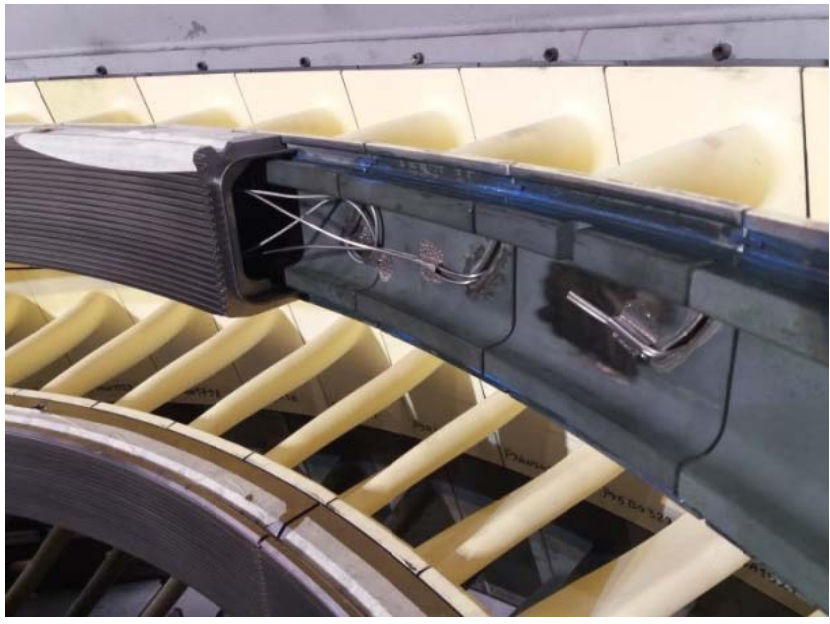

Figure 20. Typical example of SAS measurements

Performance test was performed according to (ISO 2314, 2009) before and after upgrade. In this test, such parameters as ambient pressure, temperature, and relative humidity, fuel flow rate, pressure, temperature, and composition, IGV position, shaft speed, exhaust gas pressure and temperature, and generator power are measured and thermal efficiency is calculated. Turbine power and efficiency before and after upgrade are corrected to ISO reference conditions for comparison and guarantee purposes. Performance test results indicated that both power and efficiency in the upgraded machine exceeded the expectations. The power and efficiency of the upgraded turbine corrected to ISO reference conditions were $185 \mathrm{MW}$ and $36.4 \%$ respectively. The turbine section blading polytropic efficiency has been increased more than 2.2 percentage points. It should be mentioned that the upgraded compressor vanes and blades are also installed in this machine and performance test figures are for the whole machine upgrade. 


\section{CONCLUSION}

The new turbine section upgrade introduced in MAPNA heavy-duty gas turbine MGT-70(3) can be implemented separately or together with other upgrade packages developed by MAPNA Group. It can be implemented on all previous versions of MGT-70 during standard major outages. The turbine section upgrade includes all vanes and blades, with 3D optimized airfoil and redesigned cooling system, manufactured with improved material and enhanced coatings, together with modified seal ring and baffle plate for the third vane and improved seals for vane segments and seal ring segments. The upgrade benefits include increased power output, improved thermal efficiency, extended components life, and hence reduced maintenance costs.

The first application of the full upgrade was installed and tested on a MGT-70 unit in Parand power plant. In addition to standard performance test, an extensive design validation test campaign is conducted including numerous sensors and probes for metal temperature, flow characteristics, pressure, and temperature measurement in different locations in hot gas path and SAS. During the test program, the unit is undergone a full range of operating conditions to validate the design. The data acquired from the test program are also used to calibrate the design and simulation tools. Performance test results show that the upgrade is successful and the power and efficiency surpassed the target values.

\section{NOMENCLATURE}

CCPP Combined Cycle Power Plant

CFD Computational Fluid Dynamics

CHT Conjugate heat transfer

DoE Design of Experiments

HRSG Heat Recovery Steam Generator

$\begin{array}{ll}\text { IGV } & \text { Inlet Guide Vane } \\ \text { RANS } & \text { Reynolds-Averaged Navier-Stokes } \\ \text { SAS } & \text { Secondary Air System } \\ \text { SST } & \text { Shear Stress Transport } \\ \text { TBC } & \text { Thermal Barrier Coating } \\ \text { TIT } & \text { Turbine Inlet Temperature } \\ y^{+} & \text {Non-dimensional Wall Distance }\end{array}$

\section{ACKNOWLEDGMENTS}

This work is financially supported by MAPNA Group R\&D department.

\section{REFERENCES}

Banihabib, R., and Poursamad, A. (2019). Numerical and experimental investigation of rim cavity sealing performance in a turbine stator well. Proceedings of Global Power and Propulsion Society Technical Conference 2019, GPPS-TC2019-0059.

Chew, J. W., and Hills, N. J. (2007). Computational fluid dynamics for turbomachinery internal air systems. Phil. Trans. R. Soc. A 365, 2587-2611.

Han J-C., Dutta S., and Ekkad S. (2013). Gas turbine heat transfer and cooling technology. New York: Taylor \& Francis.

ISO 2314 (2009). Gas turbines - Acceptance tests. Switzerland.

Menter, F. (1994). Two-Equtaion Eddy-Viscosity Turbulence Models for Engineering Applications. AIAA Journal Vol. 32, No. 8, 1958-1605.

Spalart, P. R., and Allmaras, S. R. (1992). A One-Equation Turbulence Model for Aerodynamic Flows. AIAA Paper 920439.

Young, J. B., and Horlock, J. H. (2006). Defining the Efficiency of a Cooled Turbine. ASME J. Turbomach. 128, 658-667. 